\title{
Yoga Practice for The Elderly: Good Choice to Avoid Falls
}

\author{
Szilvia Boros ${ }^{1 *}$, Barbara Csala ${ }^{1,2}$ and Enikő Szilágyi ${ }^{2}$ \\ ${ }^{1}$ Institute of Health Promotion and Sport Sciences, ELTE Eötvös Loránd University
}

${ }^{2}$ Doctoral School of Psychology, ELTE Eötvös Loránd University

\begin{abstract}
Received: December 30, 2017; Accepted: January 05, 2018; Published: January 12, 2018
\end{abstract}
*Corresponding author: Dr. Szilvia Boros, Institute of Health Promotion and Sport Sciences, ELTE Eötvös Loránd University,Hungary;E-mail: szilviaboros@gmail.com

\section{Abstract \\ In Western societies the last several years, practicingyoga has really become fashionable and moved from being an auxiliary way to stretch and meditate to being the go to way to improve strength, flexibility, not to mention the positive affective aspects as well. The aim of the present short communication is to highlight the impact yoga has on different areas pertaining quality of life in the elderly population, especially regarding the risks concerning falling.}

\section{Introduction}

Falls amongst older population are a global issue and have multifactorial origins [1-3]. Falls can be caused by the natural aging process, alcohol and drugs, environment or different diseases such as obesity or osteoporosis [4-6]. Fracture prevention is more relevant then fall prevention itself [6]. That is why osteoporosis is one of the most highlighted condition considering fall prevention. Almost $30 \%$ of female and $10 \%$ of male population is affected by osteoporosis worldwide [7]. Every sixth osteporosis patient suffer from fractures at least once in their lifetime. About $30 \%$ of hip fractures occur in men [8]. In osteoporosis, prevention of falls can be considered as the main goal of pervention [9].

Regular physical activity, especially weight-bearing and muscle streghtening exercise is necessary $[10,11]$. Fitness program might be based on different activities such as yoga, personalized by a physiotherapist expert $[12,13]$. In fallprevention physical therapy must be centered on improving core stability, mobility, balance, muscle strength, flexibility and bone mineral density.

Yoga is a complex science evolved over thousands of years which consists of physical, moral, mental and spiritual practices aimed at well-being of a man as whole and attaining selfawareness $[14,15]$. The most common yoga practice in Western countries is hatha yoga which involves physical postures, breathing exercises, relaxation and meditation practice [14]. A great advantage of hatha yoga is that it can be practiced at any age. There are physical postures (asanas) suitable for everybody irrespective of age or physical condition [16].

Hatha yoga has been used in clinical conditions to improve balance, strenght and flexibility at older adults [17]. Standing asanas of yoga may play important role in the improvement of core stability [18].

Silver yoga program has been invented for elderly individuals for improving flexibility [19]. The 70 minutes and the 55 minutes shortened Silver yoga intervention is devided into four parts: warm up, seven asanas, relaxation and meditation [19].

The aim of the present short communication is to highlight the importance of yoga in fall prevention.

\section{Flexibility}

As per stretching, yoga asana practice might have two ways: static and dynamic. In static form final position is held for 1-3 minutes. In dynamic form, the series of movement are repeated without held position $[20,21]$. Chen et al. conducted a Silver yoga intervention among community dwelling population for 24 weeks. Their results showed significant improvement in range of motion on the shoulder and the hip, felxibility and hand grip strenght, walking speed after the 12 weeks period [19].

Regarding the summarized result of 18 studies conducted on older individulas $(n=649)$, yoga caused improvement in selfrated mental and physical health, flexibility and aerob capacity [22].

\section{Balance}

Balance and muscle strenght play important role in fall prevention amongst the elderly [21]. Standing on one leg (static balance) is a good indicator for predicting risk of falls [18].

In the systemic review of Jeter et al. (2014) the effect of yoga on balance was analized ( $\mathrm{n}=688$, age: $18-91 \mathrm{y})$. Eleven studies (out of 15) found positive changes on balance (especially the static component) and results were independent from the time and duration of yoga. For the improvement of dynamic standing balance, yoga intervention should take more than 4 weeks in case of obese individuals [23]. In the comparison study of six yoga trials $(n=307)$, slight improvement in balance and medium improvement in mobility was detected [24]. Six months long yoga intervention caused improvement in postural balance amongst Multiple Sclerosis patients [25]. In a study of an older group with 
a history of falls ( $\mathrm{n}=39$ ), special yoga program, standard balance training and tai'chi intervention was practiced for 12 weeks [26]. Results demonstrated that all interventions were effective for the improvement of static and dynamic standing balance among older fallers. The same result was demonstrated after 8 weeks of yoga sessions in older adults [27] and in healthy young adults [28]. Improved balance function, reduced pain was detected in older individuals $(\mathrm{n}=11)$ after the 14 th week modified yoga program [29]. The study found that both balance and mobility benefited in the study of 54 community dwelling older individuals $(n=54)$ after the 12th week of twice-weekly Iyengar yoga session [30] and after the 8th week of an 80 minutes biweekly yoga program [31].

\section{Muscle strength}

Amongst elderly population there is a high prevalance of sarcopenia and has a significant impact on quality of life and mortality itself [32]. Therefore exercise intervention - especially weight bearing exercise - is essential in every day life [13]. Regarding yoga, asanas have beneficial effect on muscle strength, although huge variations might be detected at different standing poses regarding musculoskeletal demands [33]. Kumar et al found improved core stability and standing balance after 21 days of Isha yoga practice [34]. summerized that mind-body exercises, such as yoga play role in improving postural stability and functional mobility on individuals with Parkinson's disease [35].

Regular yoga practice might cause reduction in protein turnover. Even with diminshed protein breakdown and synthesis, muscle mass can be maintained amongst elderly population as well [36].

\section{Bone mineral density}

Physical inactivity has impact on the interruption of bone remodelling in consequence of bone mineral loss [13].

Bone density might be increased by yoga. Motorwala et al. found significant improvement in T-score at women in postmenopause $(n=30)$, after a half year long yoga intervention [37]. In an other study, 12 minutes daily yoga session for a period of two years caused significant increase in bone mineral density [38].

\section{Affective outcomes}

The last decades, several studies has been demonstrating the effectivness of yoga in the treatment of Posttraumatic stress disorder (PTSD), anxiety, anxiety disorders and depression [3943].

Regarding the results of a pilot study on osteoarthrosis patients $(\mathrm{N}=83), 30$ minutes daily hatha yoga practice for four times a week resulted significant reduction in anxiety and fear of falling after the 8th week [17]. Two hours weekly yoga session reduced fear of falling in older adults $(n=40)$ by the end of the second month [27].

\section{Conclusions}

Keeping active throughout life is essential in maintaining quality of life, especially in the elderly. Finding a way to exercise that is effective, safe and has multiple benefits can be daunting. Yoga appears to influence several areas, and the positive effects can be enjoyed after a relatively short period. This way novice practitioners can experience positive outcomes as well.

Most of the yoga studies have resulted positive outcome regarding balance, muscle strength, flexibility and improvement in mood, especially fear of falling. Notable is the improvement of static balance was independent from the time and duration of yoga practice. Besides the important physical aspects, several studies found improvement in affectivity as well and employed yoga in treating PTSD, anxiety, depression as well.

Besides the overall health benefits of practicing yoga, its versatility is also important. It can be practiced at home or in an organized setting, alone or in a group and can be adjusted to different mobility, flexibility or experience level. In the elderly population, where adaptability is essential, yoga seem to have a definite advantage.

\section{Acknowledgement}

This research was supported by the Hungarian National Scientific Research Fund K 124132

\section{References}

1. Brown J, Kurichi JE, Xie D, Pan Q \& Stineman MG. Instrumental activities of daily living staging as a possible clinical tool for falls risk assessment in physical medicine and rehabilitation. PM \& R: The Journal of Injury. Function and Rehabilitation. 2014;6(4):316-323. Doi:10.1016/j.pmrj.2013.10.007

2. Mitchell KD, \& Newton RA. Performance-oriented mobility assessment (POMA) balance score indicates need for assistive device. Disability and Rehabilitation. Assistive Technology. 2006;1(3):183-189.

3. Lord SR, Ward JA, Williams P, \& Anstey KJ. Physiological factors associated with falls in older community-dwelling women. Journal of the American Geriatrics Society. 1994;42(10):1110-1117.

4. Smith-Ray RL, Irmiter C, \& Boulter K. Cognitive Training among Cognitively Impaired Older Adults: A Feasibility Study Assessing the Potential Improvement in Balance. Frontiers in Public Health. 2016;4:219. Doi: 10.3389/fpubh.2016.00219

5. Mitchell RJ, Lord SR, Harvey LA, \& Close JCT. Obesity and falls in older people: mediating effects of disease, sedentary behavior, mood, pain and medication use. Archives of Gerontology and Geriatrics. 2015;60(1):52-58. Doi: 10.1016/j.archger.2014.09.006

6. Close JC. Falls in older people: Risk factors, assessment and intervention. IBMS BoneKEy. 2009;6(10):368-384. Doi: 10.1138/20090401

7. Joestl J, Lang N, Bukaty A, Tiefenboeck TM, \& Platzer P. Osteoporosis associated vertebral fractures-Health economic implications. PLoS ONE. 2017;12(5) :e0178209. Doi: 10.1371/journal.pone.0178209

8. Adler RA. Osteoporosis in men: a review. Bone Research. 2014;2:14001. Doi: 10.1038/boneres.2014.1

9. Eastell R, O’Neill TW, Hofbauer LC, Langdahl B, Reid IR, Gold DT, et. al. Postmenopausal osteoporosis. Nature Reviews. Disease Primers. 2016;2:16069. Doi: 10.1038/nrdp.2016.69

10. Giangregorio L, \& El-Kotob R. Exercise, muscle, and the applied 
load-bone strength balance. Osteoporosis International: A Journal Established as Result of Cooperation between the European Foundation for Osteoporosis and the National Osteoporosis Foundation of the USA.2016;28(1):21-33. Doi: 10.1007/s00198-016-3780-7

11. Cosman F, de Beur SJ, LeBoff MS, Lewiecki EM, Tanner B, Randall S, et.al. Clinician's Guide to Prevention and Treatment of Osteoporosis. Osteoporosis International. 2014;25(10):2359-2381. Doi: 10.1007/ s00198-014-2794-2

12. McArthur C, Laprade J, \& Giangregorio LM. Suggestions for Adapting Yoga to the Needs of Older Adults with Osteoporosis. Journal of Alternative and Complementary Medicine (New York, NY). 2016;22(3):223-226. Doi: 10.1089/acm.2014.0397

13. Smith EN, \& Boser A. Yoga, Vertebral Fractures, and Osteoporosis: Research and Recommendations. International Journal of Yoga Therapy. 2013;23(1):17-23. Doi: 10.17761/ijyt.23.1.b46687q87m790745

14. Impett EA, Daubenmier JJ. and Hirschman AL. Minding the body: yoga embodiment and well-being. Sexuality Research \& Social Policy. 2006;3(4):39-48.

15. Iyengar BKS. Light on yoga. The Aquarian Press; London: 1991.

16. Iyengar BKS. Yoga. The holistic path to health (Revised edition). DK Publishing;New York: 2014.

17. Cheung C, Wyman JF, Bronas U, McCarthy T, Rudser K, \& Mathiason MA. Managing knee osteoarthritis with yoga or aerobic/strengthening exercise programs in older adults: a pilot randomized controlled trial. Rheumatology International. 2017;37(3):389-398. Doi:10.1007/ s00296-016-3620-2.

18. Jeter PE, Nkodo AF, Moonaz SH, \& Dagnelie G. A systematic review of yoga for balance in a healthy population. Journal of Alternative and Complementary Medicine (New York, N.Y.). 2014;20(4):221-232. Doi: 10.1089/acm.2013.0378

19. Chen KM, Chen MH, Hong SM, Chao HC, Lin HS, \& Li CH. Physical fitness of older adults in senior activity centres after 24-week silver yoga exercises. Journal of Clinical Nursing. 2018;17(19):2634-2646. Doi: 10.1111/j.1365-2702.2008.02338.x

20. Srinivasan TM. Dynamic and static asana practices. International Journal of Yoga. 2016;9(1):1-3. Doi: 10.4103/0973-6131.171724

21. Bird ML, Hill KD, \& Fell JW. A randomized controlled study investigating static and dynamic balance in older adults after training with Pilates. Archives of Physical Medicine and Rehabilitation. 2012;93(1):43-49. Doi: 10.1016/j.apmr.2011.08.005

22. Patel NK, Newstead AH, \& Ferrer RL. The effects of yoga on physical functioning and health related quality of life in older adults: a systematic review and meta-analysis. Journal of Alternative and Complementary Medicine (New York, N.Y.). 2012;18(10):902-917. Doi: 10.1089/acm.2011.0473

23. Jorrakate C, Kongsuk J, Pongduang C, Sadsee B, \& Chanthorn P. Effect of yoga training on one leg standing and functional reach tests in obese individuals with poor postural control. Journal of Physical Therapy Science. 2015;27(1):59-62. Doi: 10.1589/jpts.27.59

24. Youkhana S, Dean CM, Wolff M, Sherrington C, \& Tiedemann A. Yogabased exercise improves balance and mobility in people aged 60 and over: a systematic review and meta-analysis. Age and Ageing. 2016;45(1):21-29. Doi: 10.1093/ageing/afv175
25. de Oliveira G, Tavares MdaCCGF, de Faria Oliveira JD, Rodrigues MR, \& Santaella DF. Yoga Training Has Positive Effects on Postural Balance and Its Influence on Activities of Daily Living in People with Multiple Sclerosis: A Pilot Study. Explore (New York, N.Y.). 2016;12(5):325332. Doi: $10.1016 /$ j.explore.2016.06.005

26. Ni M, Mooney K, Richards L, Balachandran A, Sun M, Harriell K,et al. Comparative impacts of Tai Chi, balance training, and a speciallydesigned yoga program on balance in older fallers. Archives of Physical Medicine and Rehabilitation. 2014;95(9):1620-1628.e30. Doi: 10.1016/j.apmr.2014.04.022

27. Nick N, Petramfar P, Ghodsbin F, Keshavarzi S \& Jahanbin I. The Effect of Yoga on Balance and Fear of Falling in Older Adults. PM \& R: The Journal of Injury. Function and Rehabilitation. 2016;8(2):145-151. Doi: 10.1016/j.pmrj.2015.06.442

28. Prado ET, Raso V, Scharlach RC, \& Kasse CA. Hatha yoga on body balance. International Journal of Yoga. 2014;7(2): 133-137. Doi: 10.4103/0973-6131.133893

29. Saravanakumar P, Higgins IJ, van der Riet PJ, Marquez J \& Sibbritt D. The influence of tai chi and yoga on balance and falls in a residential care setting: A randomised controlled trial. Contemporary Nurse. 2014;48(1):76-87. Doi: 10.5172/conu.2014.48.1.76

30. Tiedemann A, O'Rourke S, Sesto R, \& Sherrington C. A 12-week Iyengar yoga program improved balance and mobility in older communitydwelling people: a pilot randomized controlled trial. The Journals of Gerontology. Series A, Biological Sciences and Medical Sciences. 2013;68(9):1068-1075. Doi: 10.1093/gerona/glt087

31. Zettergren KK, Lubeski JM \& Viverito JM. Effects of a yoga program on postural control, mobility, and gait speed in community-living older adults: a pilot study. Journal of Geriatric Physical Therapy. 2001;34(2):88-94. Doi: 10.1519/JPT.0b013e31820aab53

32. Cruz-Jentoft AJ, Landi F, Schneider SM, Zúñiga C, Arai H, Boirie Y, et al. Prevalence of and interventions for sarcopenia in ageing adults: a systematic review. Report of the International Sarcopenia Initiative (EWGSOP and IWGS). Age and Ageing. 2014;43(6):748-759. Doi: 10.1093/ageing/afu115

33. Wang MY, Yu SSY, Hashish R, Samarawickrame SD, Kazadi L,et al. The biomechanical demands of standing yoga poses in seniors: The Yoga empowers seniors study (YESS). BMC Complementary and Alternative Medicine. 2013;13:8. Doi: 10.1186/1472-6882-13-8

34. Kumar S, Prasad S, Balakrishnan B, Muthukumaraswamy K, \& Ganesan M. Effects of Isha Hatha Yoga on Core Stability and Standing Balance. Advances in Mind-Body Medicine. 2016;30(2):4-10.

35. Kwok JYY, Choi KC, \& Chan HYL. Effects of mind-body exercises on the physiological and psychosocial well-being of individuals with Parkinson's disease: A systematic review and meta-analysis. Complementary Therapies in Medicine. 2016;29:121-131. Doi: 10.1016/j.ctim.2016.09.016

36. Colletto M, \& Rodriguez N. Routine Yoga Practice Impacts Whole Body Protein Utilization in Healthy Women. Journal of Aging and Physical Activity. 2018;26(1): 1-24. Doi: 10.1123/japa.2016-0085

37. Motorwala ZS, Kolke S, Panchal PY, Bedekar NS, Sancheti PK, \& Shyam A. Effects of Yogasanas on osteoporosis in postmenopausal women. International Journal of Yoga. 2016;9(1):44-48. Doi: 10.4103/09736131.171717 
38. Lu YH, Rosner B, Chang G, \& Fishman LM. Twelve-Minute Daily Yoga Regimen Reverses Osteoporotic Bone Loss. Topics in Geriatric Rehabilitation. 2016;32(2):81-87. Doi: 10.1097/ TGR.0000000000000085

39. Cramer H, Lauche R, Langhorst J, \& Dobos G. Yoga for depression: a systematic review and meta-analysis. Depression and Anxiety. 2013;30(11):1068-1083. Doi: 10.1002/da.22166

40. Kinser PA, Bourguignon C, Whaley D, Hauenstein E, \& Taylor AG. Feasibility, acceptability, and effects of gentle Hatha yoga for women with major depression: findings from a randomized controlled mixedmethods study. Archives of Psychiatric Nursing. 2013;27(3):137-147. Doi: 10.1016/j.apnu.2013.01.003
41. Macy RJ, Jones E, Graham LM, \& Roach L. Yoga for Trauma and Related Mental Health Problems: A Meta-Review With Clinical and Service Recommendations. Trauma Violence \& Abuse. 2015; Doi: 10.1177/1524838015620834

42. Rhodes A, Spinazzola J, \& van der Kolk B. Yoga for Adult Women with Chronic PTSD: A Long-Term Follow-Up Study. Journal of Alternative and Compleme. 2016;23(3):189-196. Doi: 10.1089/acm.2014.0407

43. Woolery A, Myers H, Sternlieb B, \& Zeltzer L. A yoga intervention for young adults with elevated symptoms of depression. Alternative Therapies in Health and Medicine. 2004;10(2):60-63. 